\title{
Analysis of heavy metals and inorganic element content in Stereospermum colais leaves
}

\author{
*Kumudhaveni Babu, Vijaya Bharathi Rajkishore, Jayshree Narayanan, Thirumal Margesan \\ Department of Pharmacognosy, College of Pharmacy, Madras Medical College, Chennai-03, Tamil Nadu, India
}

\begin{abstract}
In the present study, the presence of heavy metals (Lead, Copper, Cadmium, Arsenic and Mercury) and inorganic elements (Sulphate, Fluoride, Chloride) were quantitatively estimated from the leaves of Stereospermum colais. Lead, Copper and Cadmium were analyzed using Atomic Absorption Spectrophotometry (AAS). Arsenic was estimated by colorimetric method. Mercury was estimated by cold vapour atomic absorption method. The qualitative analysis of inorganic elements was performed. Sulphate, fluoride and chloride were quantitatively estimated by turbidimetric, colorimetric and argentometric methods, respectively. The obtained results revealed that the content of heavy metals was within the permissible levels and hence the plant was safe to be utilized in herbal drug formulation.
\end{abstract}

Key Words: Estimation, copper, cadmium, arsenic, mercury, chloride.

\section{INTRODUCTION}

Plants have been one of the important sources of medicine ever since the dawn of human civilization. The WHO has recently defined traditional medicine (including herbal drugs) as comprising therapeutic practices that have been in existence, often for hundreds of years, before the development and spread of modern medicine and are still in use today (WHO, 1991).

The use of traditional herbal medicine has spread not only in the developing countries but also in the industrialized ones, as a complementary way to treat and to prevent illnesses (World Health Organisation, 2003). Herbal medicine is a global phenomenon, a multibillion dollar industry, and its raw materials, phytochemicals are widely used as the precursors for regulated pharmaceutical products. One problematic area on both sides is in product purity, with contamination by toxic heavy metals which is one of the most common complaints. Environmental contamination by metals exerts physiological pressures that are

\footnotetext{
*Corresponding Author:

Kumudhaveni Babu

Department of Pharmacognosy, College of Pharmacy

Madras Medical College, Chennai-600 003

Tamil Nadu, India

E-mail: kumudhaveni@rediffmail.com

Contact No.: +919442410977
}

clearly too severe for survival of most species by means of phenotypic plasticity or physiological acclimation, rather than genetic adaptation (Tonguc, 1998). For example, Arsenic is known to cause arsenicosis. Inorganic arsenic compounds causes cancer, inorganic oxides of arsenic may develop cancer (Uddin, 2011). In most plants, contents of cadmium, lead, zinc and copper are observed to decrease in particular parts of a plant in the following order: root - leaves- shoots - fruits and seeds, since metals absorbed by a plant from soil first face a root barrier that impairs their penetration into aerial parts of the plant (Ciura et al., 2007). While using herbs in medicinal treatment of various illnesses, one should be aware that apart from the pharmacological effect they could turn out to be toxic because of the presence of heavy metals and other impurities. For these reasons it is essential to control the contaminants in medicinal raw materials (Baranowska et al., 2002).

\section{MATERIALS AND METHODS}

Stereospermum colais (Buch.-Ham.exDillw.) Mabberley (Bignoniaceae) is a large deciduous tree, $18-30 \mathrm{~m}$ high and $2.8 \mathrm{~m}$ in girth found throughout the moist regions of India. The leaves are useful in otalgia, odantalgia, rheumatalgia, malarial fever and wounds. The fresh leaves were collected from Vellore district, Tamil Nadu and were identified 
and authenticated by botanist Dr. P. Jayaraman, Plant Anatomical Research Centre, Tambaram, Chennai. The deposited voucher specimen number is PARC/2008/200.

\section{Estimation of heavy metals}

Flame photometry or atomic absorption spectroscopy can either be used for determining the heavy metals. Atomic absorption method was capable of determining metal concentration ranging from trace to major constituent levels. The fine powder was used for dry ashing (Padmaja, 2012).

\section{Estimation of Arsenic}

A suitable sample was placed in a flask. Then $7 \mathrm{ml}$ of Sulphuric acid and $5 \mathrm{ml}$ of conc. Nitric acid was added. An excess of nitric acid was maintained until the organic matter was destroyed. Arsenic was estimated by using Modified Arsenic estimation apparatus. Sample was taken in an arsine generator. $3 \mathrm{~g}$ of Zinc and $2 \mathrm{ml}$ of potassium iodide solution was added to the generator. The glass wool was impregnated in the scrubber with lead acetate solution. $4 \mathrm{ml}$ of silver diethyl dithiocarmate reagent was taken in the absorber tube. $5 \mathrm{ml}$ of conc. Hydrochloric acid and $1 \mathrm{ml}$ of stannous chloride reagent was taken in a measuring cylinder. The generator scrubber absorber assembly was connected and ensured that all other connections were tightly fitted. The stopper of arsine generator was removed and the generator was immediately closed with the stopper and allowed 30 minutes for complete evolution of arsine. Solution was poured from the absorber directly in to $1 \mathrm{~cm}$ cell and the absorbance of the solution was measured at 535nm spectrophotometrically. Standard curve was prepared by using the standard solution (Manual on water and waste water analysis).

\section{Estimation of Mercury}

Mercury was estimated by cold vapour atomic absorption method (wet basis) using Mercury Analyser ECIL MA 5840. All the control knobs present in the instrument were adjusted. The stopper was removed. A suitable aliquot of the blank, standard or sample solution were taken in the reaction vessel. $10 \%$ Nitric acid was added to maintain a volume of $100 \mathrm{ml} .2 \mathrm{ml}$ of stannous chloride was also added and the stopper was replaced immediately. Magnetic stirrer was switched on and stirred vigorously for about $5 \mathrm{~min}$ and then adjusted to ' 0 ' and $100 \% \mathrm{~T}$. The filter rod was left in the position. 'HOLD' mode of operation was switched on. The pump was started and air was allowed to purge through the reaction vessel. The absorbance was noted as early as possible with in a min and switched back to 'NORMAL MODE'. The meter indication should be back to $100 \% \mathrm{~T}$. The pump and the magnetic stirrer were switched off. Before each measurement it was adjusted with $0 \%$ and $100 \%$. Measurements were repeated for standard also (Clesceri et al., 1998).

\section{Estimation of Lead, Copper and Cadmium}

Lead, Copper and Cadmium was estimated by Flame Atomic Absorption Spectroscopy (Direct Air -Acetylene Flame Method). The digestion technique was followed to reduce the interference by organic matter and also to convert the metals associated with particulates to free metal. Nitric acid was used to digest the samples. The instrument used for analysis was Perkin Elmer Analyser 300. After calibrating the instrument, a blank consisting of deionized water containing the same concentration of acid in standard and sample was aspirated and then instrument was adjusted to Zero. Standard solution was also aspirated and the aspiration rate of the nebulizer was adjusted to obtain maximum sensitivity. Burner was adjusted both vertically and horizontally to obtain maximum response. Blank was aspirated again and rezero the instrument. The same was repeated for sample and its absorbance was determined (Clesceri et al. 1998).

The metal concentration was estimated on dry weight basis by using the following equation:

Metal Concentration $=\left(\frac{A \times B}{g}\right) \times(100 / D)$

where, metal concentration in $\mathrm{mg} / \mathrm{kg}$ (dry weight basis)

A- concentration of metal in digested solution, $\mathrm{mg} / \mathrm{l}$

B- final volume of digested solution

D- total solids in \%.

g- weight taken

\section{Estimation of inorganic elements Qualitative analysis}

Ash of drug material was prepared and treated with $50 \% \mathrm{v} / \mathrm{v} \mathrm{HCl}$ for 1 hour. After the filtration, the filtrate was used to perform the following tests (Khandelwal 2006): 
Calcium: One drop of dil. ammonium hydroxide and saturated ammonium oxalate solution was added to $10 \mathrm{ml}$ of the above filtrate. White precipitates of calcium oxalate, soluble in hydrochloric acid but insoluble in acetic acid, were formed.

Magnesium: White calcium oxalate precipitate was separated by filtering the above solution. The filtrate was heated and cooled. Solution of sodium phosphate in dilute ammonia solution was added. White crystalline precipitate was observed.

Sodium: Little uranyl magnesium acetate reagent was added to $2 \mathrm{ml}$ of the test solution, shaken well and kept for few minutes. Yellow crystalline precipitate of sodium magnesium uranyl acetate was observed.

Potassium: Few drops sodium cobalt nitrite solution was added to $2-3 \mathrm{ml}$ of the test solution. Yellow precipitate of potassium cobalt nitrite was observed.

Iron: Few drops of $2 \%$ potassium ferrocyanide were added to $5 \mathrm{ml}$ of the test solution. Dark blue coloration was observed.

Sulphate: To $5 \mathrm{ml}$ of the test solution, lead acetate reagent was added. A white precipitate, soluble in sodium hydroxide, was formed.

Phosphate: $5 \mathrm{ml}$ of test solution was prepared in nitric acid and a few drops of ammonium molybdate solution were added. It was heated for about 10 minutes and left to be cooled. A yellow crystalline precipitate of ammonium molybdate was observed.

Chloride: 3 to $5 \mathrm{ml}$ of lead acetate solution was added to about 5 to $7 \mathrm{ml}$ of the filtrate. A white precipitate soluble in hot water was observed.

Carbonate: To $5 \mathrm{ml}$ of the test solution, dilute acid was added. Carbon dioxide was liberated from the solution.

Nitrates: Ferrous sulphate solution was added to $5 \mathrm{ml}$ of the test solution. No brown colour was produced, but when sulphuric acid was added (slowly from the side of the test tube), a brown colored ring was produced at the junction of two liquids.

\section{Quantitative analysis (Clesceri et al. 1998)}

Sulphate: Sulphate was estimated by Turbidimetric method based upon the precipitation of Sulphate ion in an acetic acid medium with barium chloride so as to form barium sulphate crystals of uniform size. A suitable portion of sample was taken in a $250 \mathrm{ml}$ Erlenmeyer flask. Then $20 \mathrm{ml}$ of buffer solution was added to the sample and mixed in stirring apparatus. A spoonful of barium chloride crystals was added while stirring, and timing was begun immediately. It was stirred for $60 \pm 2 \mathrm{~s}$ at constant speed. After stirring period has ended, the solution was poured into the absorption cell of spectrophotometer and turbidity was measured at $420 \mathrm{~nm}$. Light absorbance of the barium sulphate suspension was measured and the sulphate concentration was determined by comparison of the reading with a standard curve using Chemito 2100 scanning spectrometer.

Fluoride: Fluoride was estimated by sodium 2(parasulfophenylazo)- 1,8-dihydroxy-3,6-naphthalene disulphonate (SPADNS) colorimetric method and it is based on the reaction between fluoride and a zirconium-dye lake. Fluoride reacts with the dye lake, dissociating a portion of it into a colorless complex anion $\left(\mathrm{ZrF}_{6}{ }^{2}\right)$; and the dye. As the amount of fluoride increases, the color produced becomes progressively lighter. Absorbance was measured using Chemito 2100 scanning spectrometer. Fluoride standards in the range of 0 to $1.40 \mathrm{mg} \mathrm{F}-/ \mathrm{L}$ was prepared by diluting appropriate quantities of standard fluoride solution to $50 \mathrm{ml}$ with distilled water. $5 \mathrm{ml}$ each of SPADNS solution and zirconyl-acid reagent or $10 \mathrm{ml}$ mixed acid-zirconyl-SPADNS reagent, was pipetted to standard and mixed well. Contamination was avoided. Photometer was set to zero absorbance with the reference solution and the absorbance reading of standard was noted. Residual chlorine was removed by adding 1 drop $(0.05 \mathrm{ml}) \mathrm{NaAsO}_{2}$ solution/ $0.1 \mathrm{mg}$ residual chlorine and mixed. A portion of sample was diluted to $50 \mathrm{ml}$ with distilled water. Sample temperature was adjusted to that used for the standard curve. $5 \mathrm{ml}$ each of SPADNS solution and zirconyl-acid reagent, or $10 \mathrm{ml}$ acid-zirconyl-SPADNS reagent was added; mixed well and the absorbance at $570 \mathrm{~nm}$ was noted.

Chloride: Chloride was estimated by Argentometric method. In a neutral or slightly alkaline solution, potassium chromate can indicate the end point of the silver nitrate titration of chloride. Silver chloride will be precipitated quantitatively before red silver chromate is formed. A suitable portion of sample was diluted to $100 \mathrm{ml}$ and $3 \mathrm{ml}$ of aluminium hydroxide suspension was added if and only if the sample was 
Table 1: Quantitative estimation of heavy metals.

\begin{tabular}{ccc}
\hline S1. No. & Parameters & Quantity $(\mathbf{m g} / \mathbf{k g})$ \\
\hline 1 & Lead (DB) & $<0.015$ \\
2 & Copper (DB) & $<0.0015$ \\
3 & Cadmium (DB) & $<0.0008$ \\
4 & Arsenic (DB) & $<0.001$ \\
5 & Mercury (WB) & $<0.005$ \\
\hline
\end{tabular}

DB - Dry basis, WB - Wet Basis

highly colored. Mixed, let aside to get settled and filtered. $\mathrm{pH}$ was adjusted to 7 to 10 and the samples in the $\mathrm{pH}$ range 7 to 10 were directly titrated. $1 \mathrm{ml}$ of potassium chromate indicator solution was added and titrated with standard silver nitrate titrant up to a pinkish yellow end point.

\section{RESULTS AND DISCUSSION}

The heavy metals are present naturally in the soil. They are non-degradable and can be accumulated in the plant tissues. The metals chosen for this study were Arsenic, Mercury, Lead, Copper and Cadmium since they are extremely toxic even in very small amounts. The results of the quantitative estimation of heavy metals are presented in table 1 . The concentration of heavy metals was within the permissible levels. The presence of essential element copper in the leaves confirms the potentiality of the drug in various ailments. The results of the qualitative and quantitative estimation of inorganic elements content in this medicinal plant are presented in table 2. Mineral content indicates the nutritive value and potentially act as a cofactor for the biological activity exhibited by the plant extracts studied.

\section{CONCLUSION}

This study suggests that this plant is safe to utilize as herbal drug, since the concentration of heavy metals is within the limits. The concentration of trace nutrients plays a key role in secondary metabolite production in the plants which further decides the quality of herbal raw material. The present study furnishes worthy information for validation of this medicinally useful plant. Hence, Sterospermum colais leaves can be utilized in herbal drug formulation.
Table 2: Qualitative and quantitative estimation of inorganic elements.

\begin{tabular}{cccc}
\hline Sl. No. & Inorganic elements & Observation & $\begin{array}{c}\text { Quantity } \\
(\mathbf{m g} / \mathbf{k g})\end{array}$ \\
\hline 1 & Calcium & - & \\
2 & Magnesium & + & \\
3 & Sodium & - & \\
4 & Potassium & - & \\
5 & Iron & + & \\
6 & Sulphate & + & $995(\mathrm{WB})$ \\
7 & Phosphate & + & \\
8 & Chloride & + & $27,674(\mathrm{WB})$ \\
9 & Carbonate & - & \\
10 & Nitrate & - & \\
11 & Fluoride & + & $<0.1(\mathrm{WB})$ \\
\hline
\end{tabular}

(+) Present, (-) Absent, WB- wet basis

\section{ACKNOWLEDGEMENT}

Authors are thankful to Mr. P. V. Marimuthu, Assistant Director (lab), Tamil Nadu Pollution Control Board, Chennai, India for providing facilities to conduct research work.

\section{REFERENCES}

Baranowska, I., Srogi, K., Wlochowicz, A.Szczepanik, K. (2002). Determination of Heavy Metal contents in samples of Medicinal Herbs. Polish Journal of Environmental Studies, Volume 11, Issue 5, pages 467-471.

Ciura, D.F., Lozna, K, Styczyńska, M., (2007). Cadmium, lead, zinc and copper contents in selected vegetables and fruit from garden allotments of the south-western Poland. Polish Journal of Food and Nutrition Sciences, Volume 57, Issue 4(A), pages. 137-143.

Clesceri, L.S., Green berg, AE. \& Eaton, AD. (1998). Standard methods for the Examination of water and waste water $\left(20^{\text {th }}\right.$ edition). American Public Health Association, Washington.

Khandelwal, K.R (2006) Practical Pharmacognosy (16 ${ }^{\text {th }}$ ed.,) Nirali Prakashan, Pune.

Manual on water and waste water analysis. Natural Environmental Engineering Research Institute, Nehru Marg, Nagpur.

Padmaja, D., Kannappan N., (2012) Standardization of traditionally designed neutraceutical. International Current Pharmaceutical Journal, Volume 1, Issue 9, pages 288-293. [DOI]

Tonguc, O. (1998) Determination of Heavy metal levels in some moss species Around Thermic power Stations. Turkey Journal of Biology, Volume 28, pages 171-180.

Uddin, R., Saffoon, N, Alam, M.A. (2011) Arsenic, the poison and poisoned groundwater of Bangladesh. International Current Pharmaceutical Journal, volume 1, issue 1, pages 12-17. [DOI]

WHO (1991) ‘WHO, in progress report by the Director General, Document no. A44/20, 22 March, World Health Organization, Geneva.

World Health Organization (2003). Traditional Medicine, Fact sheet No. 134. Available at: [Link] [Accessed on: 07/01/2013]. 